\title{
An unusual case of persisting hypoxia in a patient with a thrombolysed pulmonary embolism
}

\author{
Authors: Sanjoy Ray, ${ }^{A}$ Shakeel A Qureshi, ${ }^{B}$ Natalie Stolagiewicz, ${ }^{C}$ Lydia Sturridge ${ }^{D}$ and Sitara Khan ${ }^{\mathrm{D}}$
}

\begin{abstract}
Exertional breathlessness and hypoxia are common presenting complaints in acute medicine. We describe a case where the patient continued to have persistent hypoxia even after the primary cause (pulmonary embolism) was diagnosed and treated. The hypoxia persisted as an enigma, its cause remaining elusive till diagnosed. Standard firstline investigations would not have reached the underlying diagnosis in this case and, as such, it demonstrates the keen clinical sense and complex investigative strategy required to solve the puzzle.
\end{abstract}

KEYWORDS: Hypoxia, pulmonary embolism, platypnoea, orthodeoxia, echocardiography

DOI: $10.7861 /$ clinmed.2020-0753

\section{Introduction}

Acute pulmonary embolism (PE) is a leading cause of cardiovascular death. Submassive or intermediate-risk PE is diagnosed on the basis of haemodynamic status in conjunction with evidence of cardiac dysfunction, shown either on cardiothoracic imaging or with elevated serum cardiac biomarkers. Acute management options include anticoagulation alone or in combination with systemic thrombolytic therapy. Persistent hypoxia in cases of treated PE should alert physicians to an additional pathology and subtle clinical signs like platypnoea and orthodeoxia can aid in the diagnosis.

\section{Case presentation}

An 86-year-old woman presented with sudden onset dyspnoea and dizziness which woke her up from sleep. She had no chest pain or syncope. She had a past history of cerebrovascular accident in 2007 with no residual deficit and a deep vein thrombosis a year ago, for which she had received anticoagulation for 6 months. She lived alone, was independent and able to walk long distances,

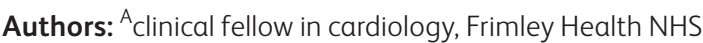
Foundation Trust, Camberley, UK; ${ }^{B}$ consultant paediatric cardiologist, Evelina London Children's Hospital, London, UK; ${ }^{C}$ consultant respiratory physician, Frimley Health NHS Foundation Trust, Camberley, UK; ${ }^{\mathrm{D}}$ consultant cardiologist, Frimley Health NHS Foundation Trust, Camberley, UK did her own gardening and had never smoked. Her medication comprised clopidogrel and a statin. On presentation, she had sinus tachycardia at 112 beats/min with blood pressure of 138/84 $\mathrm{mmHg}$, afebrile with respiratory rate (RR) 22 breaths/min, but hypoxic with an oxygen saturation $\left(\mathrm{SpO}_{2}\right)$ of $90 \%$ on $3 \mathrm{~L} / \mathrm{min}$ oxygen. She had a tender, swollen left calf. Respiratory system examination was unremarkable with no peripheral or central cyanosis. There were no audible murmurs.

Routine blood tests were all unremarkable except for elevated D-dimer $>1,000 \mathrm{ng} / \mathrm{mL}$ (0-500), N-terminal pro B-type natriuretic peptide at $807 \mathrm{ng} / \mathrm{L}(0-299)$ and high-sensitivity troponin I at 61 ng/L (0-46). Twelve-lead electrocardiography (ECG) showed sinus tachycardia with right bundle branch block and T-wave inversions in leads $V_{1}-V_{4}($ Fig 1$)$. Chest $X$-ray only showed dependent changes in the lung bases.

A clinical diagnosis of possible pulmonary embolism was made and computed tomography pulmonary angiography (CTPA) confirmed bilateral lobar pulmonary arterial emboli, more extensive on the right (Fig 2). She was started on treatment of low molecular weight heparin and admitted to the ward on high flow oxygen. Computed tomography (CT) of the abdomen and pelvis was negative for malignancy.

On day 1 post-admission, she was too dyspnoeic to mobilise, with $\mathrm{SpO}_{2}$ of $99 \%$ on $4 \mathrm{~L} / \mathrm{min}$ oxygen. She had a brief unresponsive episode with arterial blood gas (ABG) showing worsening type 1 respiratory failure with a partial pressure of oxygen $\left(\mathrm{pO}_{2}\right)$ of $12 \mathrm{kPa}$ on $15 \mathrm{~L} / \mathrm{min}$ oxygen. She was then thrombolysed with alteplase and transferred to the high-dependency unit, where her saturation improved to $96 \%$ on $4 \mathrm{~L} /$ min oxygen. Transthoracic echocardiography showed normal left ventricular size with hyperdynamic function. The right side of the heart appeared normal but in the context of suboptimal visualisation, with no significant valvular disease.

On day 4 , her oxygen requirement worsened with saturation dropping to $82 \%$ on $15 \mathrm{~L} / \mathrm{min}$ oxygen. Repeat CTPA showed resolution of the pulmonary emboli. Over the next 7 days, she continued to be oxygen-dependent with fraction of inspired oxygen $\left(\mathrm{FiO}_{2}\right)$ of $4 \mathrm{~L} / \mathrm{min}$. A week later, she had an acute deterioration in oxygen saturation, with $\mathrm{SpO}_{2}$ dropping to $78 \%$ on $4 \mathrm{~L} /$ min oxygen, thus requiring continuous positive airway pressure ventilation. Venous Doppler ultrasound of both legs was negative for thrombus.

She was noted to be much more hypoxic and dyspnoeic on sitting up ( $\mathrm{SpO}_{2}$ at $80 \%$ on $2 \mathrm{~L} / \mathrm{min}$ oxygen), compared with lying supine $\left(\mathrm{SpO}_{2}\right.$ at $92 \%$ on $2 \mathrm{~L} / \mathrm{min}$ oxygen). In view of this, 


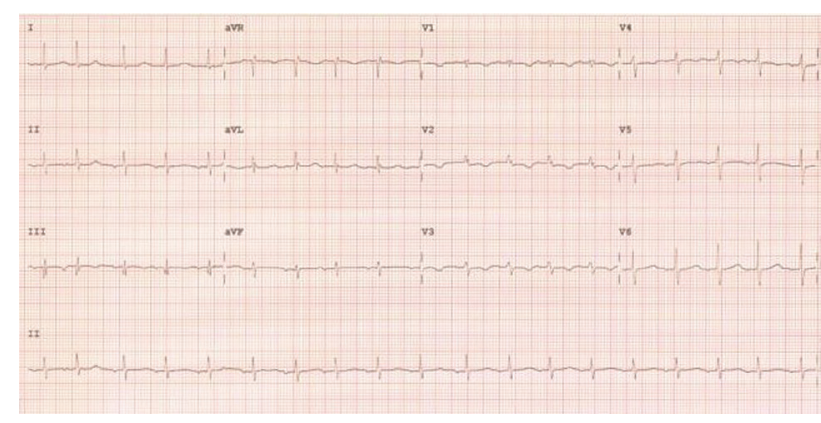

Fig 1. Twelve-lead electrocardiography showing sinus tachycardia with right bundle branch block and $T$-wave inversions in leads $V_{1}-V_{4}$.

a right-to-left shunt was suspected and so she underwent a bubble transthoracic echocardiography. On injection of agitated blood/saline, there was passage of $>15$ bubbles across the interatrial septum within three cardiac cycles indicating an interatrial shunt. In order to assess the interatrial septum in more detail, a transoesophageal echocardiography (TOE) was performed, which confirmed a patent foramen ovale (PFO), with a large intermittent communication between the left and right atria, and clear right-to-left shunting on both colour flow Doppler ultrasound (Fig $3 a$ ) and with agitated blood/saline mixture (Fig 3b).

\section{Treatment and outcome}

She was transferred to a tertiary cardiac centre, where she underwent successful percutaneous PFO closure with a $28.5 \mathrm{~mm}$ Flex II Uni Occluder (Occlutech, Helsingborg, Sweden; Fig 4). On balloon sizing, the PFO measured $13 \mathrm{~mm}$ in diameter. The pulmonary artery pressure was $30 / 11 \mathrm{mmHg}$ compared with aortic pressure of $110 / 70 \mathrm{mmHg}$. There was no residual shunt after the procedure. Her oxygen requirements resolved almost immediately after the closure was performed. She was doing well on review a month later.

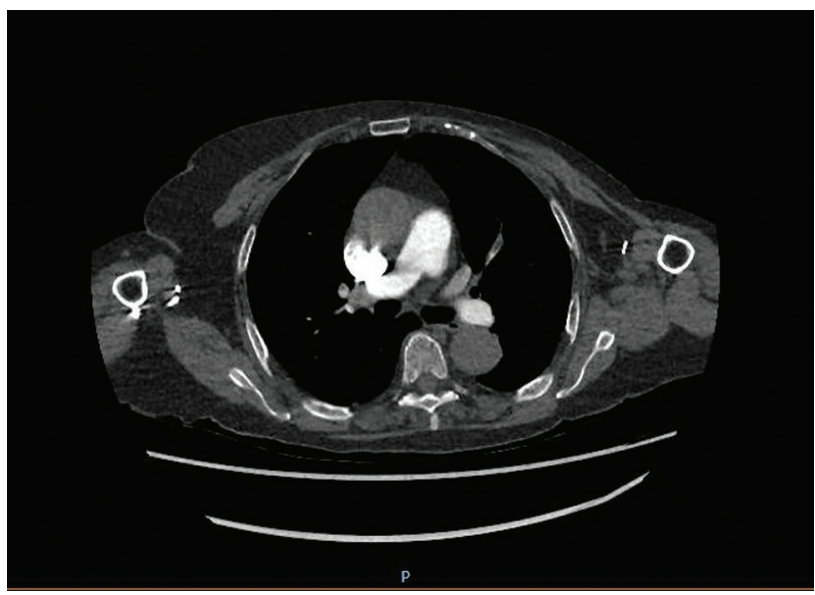

Fig 2. Computed tomography pulmonary angiography confirming bilateral lobar pulmonary arterial emboli, more extensive on the right.
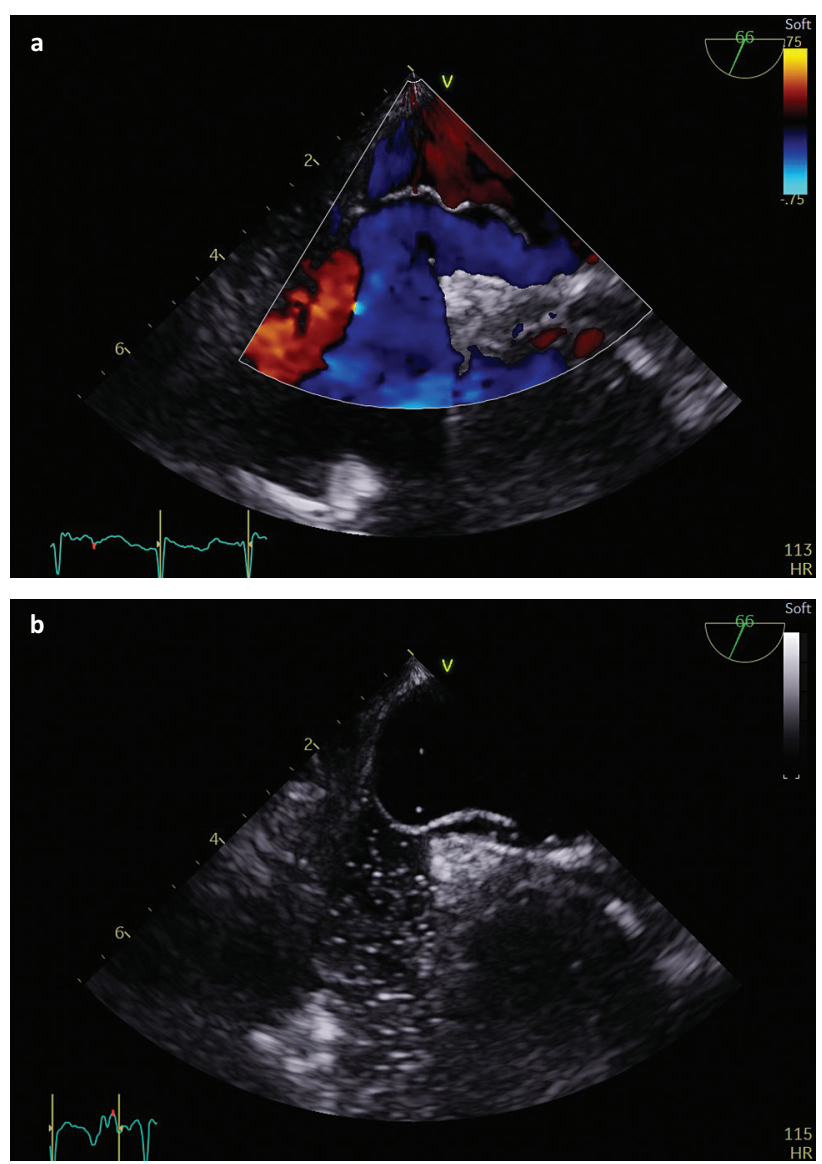

Fig 3. Transoesophageal echocardiography demonstrating a patent foramen ovale with a large intermittent communication between the left and right atria and clear right-to-left shunting. a) Colour flow Doppler ultrasound. b) Agitated blood/saline mixture ultrasound.

\section{Discussion}

Platypnoea-orthodeoxia syndrome is a rare clinical syndrome first described by Burchell et al in 1949 and is frequently used to describe the syndrome of abnormal oxygenation in the upright position. 'The word 'platypnoea' refers to dyspnoea
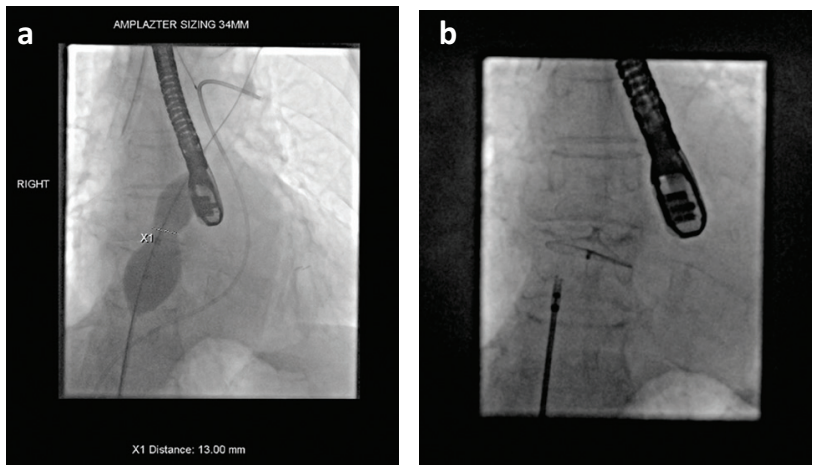

Fig 4. Percutaneous patent foramen ovale (PFO) closure with an occluder. a) Balloon interrogation and sizing of PFO. b) Occlutech Flex II Uni Occluder released in PFO. 
induced by an upright posture and relieved by recumbence. This is clinically demonstrated by orthodeoxia, namely, arterial oxygen desaturation that is incurred by an upright posture and improved by a recumbent one. Several mechanisms have been postulated. They fall into three main categories: intracardiac shunting, pulmonary vascular shunting and ventilation-perfusion mismatching. $^{2}$

On the basis of autopsy studies, approximately $35 \%$ of the general population have a probe-PFO, and $5-10 \%$ have a flowPFO. ${ }^{3}$ Although PFO may be clinically silent for decades, patients with this defect may present with platypnoea-orthodeoxia syndrome. One reason for this is a change in the position of the aorta relative to the heart with age. The elongation and dilatation of the aorta in elderly patients (often seen as 'unfolding' on a chest X-ray) may cause the atrial septum to become horizontal, thereby promoting a more direct pathway for blood flow from the vena cava through the interatrial communication, despite the absence of a pressure gradient. ${ }^{4-6}$ The upright position can stretch the interatrial communication, allowing more streaming of venous blood from the inferior vena cava through the defect. ${ }^{\text {. }}$

An otherwise clinically silent PFO can also manifest with the platypnoea-orthodeoxia syndrome secondary to a pulmonary embolism, as in our case. ${ }^{8}$ In acute pulmonary embolism, the PFO acts as a 'pop-off valve' such that the right atrial pressure increases, causing a right-to-left shunt and persisting hypoxia. ${ }^{3}$ The presence of PFO was associated with a significantly lower arterial $\mathrm{pO}_{2}$ among 85 patients with a haemodynamically significant pulmonary embolism, in whom there was a $39 \%$ prevalence of PFO. ${ }^{9,10}$ Chronic thromboembolic pulmonary hypertension (CTEPH) is the end result of persistent obstruction of the pulmonary arteries by acute or recurrent pulmonary emboli. In a prospective study, $3.8 \%$ of 314 consecutive patients who presented with acute pulmonary emboli developed symptomatic pulmonary hypertension within 2 years. The cumulative incidence of symptomatic CTEPH was $1 \%$ at 6 months and $3.1 \%$ at 1 year. No new cases developed after 2 years. ${ }^{11}$ In our case, the ECG changes and blood results indicated right heart strain.

The diagnosis of platypnoea-orthodeoxia is made by demonstrating desaturation in the upright position that improves on lying flat, and the demonstration of a right-to-left shunt by any of four diagnostic modalities: a TOE with bubble study, 99mTcmacroaggregated albumin scan, pulmonary arteriography to show intrapulmonary vascular dilatation or right heart catheterisation. The TOE with bubble study is the most sensitive non-invasive test. It visualises the interatrial septum clearly and, in some patients, flow across the PFO can be seen with colour flow Doppler ultrasound. Sensitivity is increased by injecting agitated saline (bubbles) through a large peripheral vein, and the subsequent passage of bubbles is seen across the PFO and into the left side of the heart within the first three cardiac cycles. ${ }^{2,12,13}$ If the patient is asked to cough or perform the Valsalva manoeuvre during the TOE, this increases the intrathoracic pressure and unmasks rightto-left shunting if clinical suspicion remains. This can be achieved in the ventilated patient by increasing the positive end-expiratory pressure. It should be noted that right heart catheterisation can yield false negative results as the patient is in the supine position; indeed, we took extra care to position the patient semi-upright for the TOE once she had swallowed the probe, so that the suspected pathology would not be missed.

The definitive treatment for cardiac platypnoea-orthodeoxia syndrome is percutaneous closure of the interatrial communication, which appears to be safe and efficient, and with a low rate of complication. ${ }^{14}$ Pulmonary hypertension should be excluded before closure of the defect, as in our patient, to avoid clinical deterioration of the patient's condition after correction of right-toleft-shunt.

\section{Summary}

Persistent hypoxia in cases of acute pulmonary embolism should alert clinicians to the possibility of an intracardiac shunt, such as a PFO. The diagnosis involves a high level of clinical suspicion. We conclude that our patient's PFO became manifest when her right heart pressures increased following the development of pulmonary embolism.

\section{Key points}

> If a patient has hypoxia and dyspnoea that worsen when upright compared to supine, suspect a shunt at cardiac or pulmonary level. Exclude associated clubbing and liver disease.

$>$ A high index of suspicion is necessary and measurement of saturation/arterial blood gases in supine and upright positions should be made to document orthodeoxia.

> Bubble transoesophageal echocardiography is an important tool in aiding the diagnosis.

$>$ As experience with catheter-based treatment increases, more and more patients with the platypnoea-orthodeoxia syndrome are being referred for closure of their patent foramen ovale.

\section{Acknowledgements}

The authors would like to thank the patient and her family for their whole-hearted cooperation and trust placed by them during the whole course of her hospital stay and treatment.

\section{References}

1 Burchell HB, Helmholz HF Jr, Wood EH. Reflex orthostatic dyspnea associated with pulmonary hypotension (abstract). Am J Physiol 1949;159:563-4.

2 Chen GP, Goldberg SL, Gill EA Jr. Patent foramen ovale and the platypnea-orthodeoxia syndrome. Cardiol Clin 2005;23:85-9.

3 Liew J, Stevens ], Slatore C. Refractory hypoxemia in a patient with submassive pulmonary embolism and an intracardiac shunt: a case report and review of the literature. Perm J 2018;22:17-061.

4 Cheng TO. Platypnea-orthodeoxia syndrome: etiology, differential diagnosis, and management. Cathet Cardiovasc Interv 1999;47:64-6.

5 Kusunose K, Yamada H, Todoroki T et al. Platypnea-orthodeoxia syndrome associated with patent foramen ovale and aortic ectasia. Echocardiography 2009;26:114-7.

6 Shiraishi Y, Hakuno D, Isoda K, Miyazaki K, Adachi T. Platypneaorthodeoxia syndrome due to PFO and aortic dilation. JACC Cardiovasc Imaging 2012;5:570-1.

7 Cheng TO. Mechanisms of platypnea-orthodeoxia: What causes water to flow uphill? Circulation 2002;105:e47.

8 Seward JB, Hayes DL, Smith HC et al. Platypnea-orthodeoxia: clinical profile, diagnostic work up, management, and report of seven cases. Mayo Clin Proc 1984;59:221-31.

9 Kasper W, Geibel A, Tiede N, Just H. Patent foramen ovale in patients with haemodynamically significant pulmonary embolism. Lancet 1992;340:561-4.

10 Brydon C, Fawcett W], Treasure T, Clarke JT. Pulmonary embolus and patent foramen ovale: a rare cause of refractory hypoxaemia. $\mathrm{Br}$ J Anaesth 1993;71:298-300. 
11 Pengo V, Lensing AW, Prins MH et al. Incidence of chronic thromboembolic pulmonary hypertension after pulmonary embolism. $N$ Engl J Med 2004;350:2257-64.

12 Desouza KA, Saraswat S, DeSouza SA et al. Platypnea-orthodeoxia syndrome: a diagnostic challenge. South Med J 2009;102:1046-8.

13 Marples IL, Heap MJ, Suvarna SK, Mills GH. Acute right-to-left interatrial shunt; an important cause of profound hypoxia. $\mathrm{Br}$ ] Anaesth 2000;85:921-5.

14 Blanche C, Noble S, Roffi M et al. Platypnea-orthodeoxia syndrome in the elderly treated by percutaneous patent foramen ovale closure: a case series and literature review. Eur ] Intern Med 2013;24:813-7.

Address for correspondence: Dr Sanjoy Ray, Cardiology Department, Frimley Health NHS Trust, Portsmouth Road, Camberley, Surrey GU16 7UJ, UK.

Email:drsanjoyray@yahoo.com

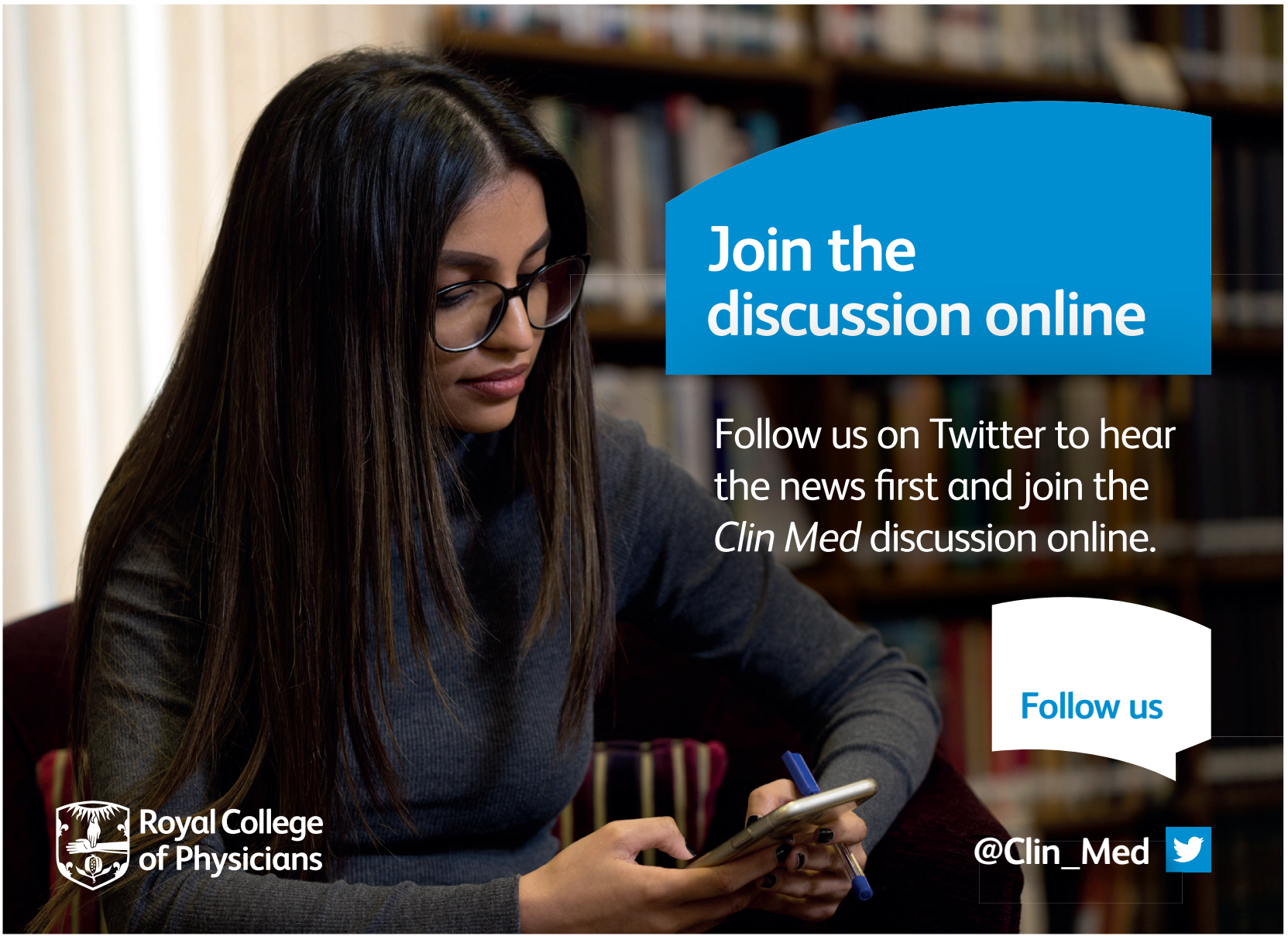

